Portland State University

PDXScholar

\title{
PTSD Symptomology and Motivated Alcohol Use Among Military Service Members: Testing a Conditional Indirect Effect Model of Social Support
}

\author{
Cameron T. McCabe \\ Portland State University \\ Cynthia Mohr \\ Portland State University, cynthia.mohr@pdx.edu \\ Leslie B. Hammer \\ Portland State University, hammerl@pdx.edu \\ Kathleen F. Carlson \\ Oregon Health \& Science University
}

Follow this and additional works at: https://pdxscholar.library.pdx.edu/psy_fac

Part of the Psychology Commons

Let us know how access to this document benefits you.

\section{Citation Details}

McCabe, C. T., Mohr, C. D., Hammer, L. B., \& Carlson, K. F. (2019). PTSD Symptomology and Motivated Alcohol Use Among Military Service Members: Testing a Conditional Indirect Effect Model of Social Support. Substance Use \& Misuse, 54(2), 257-270.

This Post-Print is brought to you for free and open access. It has been accepted for inclusion in Psychology Faculty Publications and Presentations by an authorized administrator of PDXScholar. Please contact us if we can make this document more accessible: pdxscholar@pdx.edu. 
PTSD symptomology and motivated alcohol use among military service members: Testing a conditional indirect effect model of social support

Cameron T. McCabe, Ph.D ${ }^{1}$; Cynthia D. Mohr, Ph.D ${ }^{1}$; Leslie B. Hammer, Ph.D. ${ }^{1,2}$; Kathleen F. Carlson, Ph.D. ${ }^{2,3}$

${ }^{1}$ Portland State University; ${ }^{2}$ Oregon Health \& Science University; ${ }^{3}$ Veterans Affairs (VA) Portland Healthcare System

Note: Correspondence concerning this article should be addressed to Cameron T. McCabe, Medical Modeling, Simulation, and Mission Support Department, Naval Health Research Center, 140 Sylvester Road, San Diego, CA 92106-; e-mail: cameron.mccabe@ gmail.com. The U.S. Army Medical Research Acquisition Activity, 820 Chandler Street, Fort Detrick MD 217025014 is the awarding and administering acquisition office. This work was supported by the Office of the Assistant Secretary of Defense for Health Affairs, through the USAMRMC Broad Agency Announcement under Award No. W81XWH-13-2-0020. Opinions, interpretations, conclusions and recommendations are those of the author and are not necessarily endorsed by the Department of Defense. Portions of this research were supported by the Grant \# T03OH008435 awarded to Portland State University, funded by the Centers for Disease Control and Prevention, National Institute for Occupational Safety and Health. Its contents are solely the responsibility of the authors and do not necessarily represent the official views of NIOSH, CDC or HHS 


\begin{abstract}
Background: Posttraumatic stress disorder (PTSD) and problematic alcohol use commonly cooccur among military service members. It remains critical to understand why these patterns emerge, and under what conditions. Objectives: This study examined whether PTSD symptoms (PTSS) and alcohol involvement (quantity and frequency of use, heavy episodic drinking, and alcohol problems) are indirectly related through four distinct drinking motivations. A secondary aim was to identify factors, specifically forms of social support, which buffer these associations. Methods: Using baseline data from a randomized-controlled trial of health and well-being among civilian-employed separated service members and reservists, the present study examined these issues using a subsample of 398 current drinkers. Results: Parallel mediation models revealed PTSS-alcohol consumption associations were indirect through coping and enhancement motivations. PTSS was only related to alcohol problems through coping motivations. In addition, the indirect effect of PTSS on average level of consumption via coping motives was conditional on perceived support from friends and family, whereas the indirect effect for alcohol problems was conditional only on friend support. In contrast, the indirect effects of PTSS on alcohol consumption variables (but not problems) via enhancement motives were conditional on perceived support from friends and family. Conclusions/Importance: Future research and screening efforts should attend to individual motivations for drinking as important factors related to alcohol use and problems among service members experiencing PTSS, and emphasize the importance of communication, trust, and effective supports among military and nonmilitary friends and family.
\end{abstract}

Keywords: military service members, PTSD, alcohol, drinking motives, social support 


\section{Introduction}

Events experienced during military deployments can lead to deleterious mental and physical health outcomes (Hoge et al., 2007; King et al., 1999). Prevalence of posttraumatic stress disorder (PTSD) among service members from Operations Enduring Freedom and Iraqi Freedom (OEF/OIF) is estimated at about 20\% (Tanielian \& Jaycox, 2008). Comorbidity between PTSD and alcohol misuse and problems is high (IOM, 2014; Thomas et al., 2010), and co-occurrence of PTSD and alcohol use disorders may mutually exacerbate associated symptoms, contributing to poor treatment prognosis (Foa \& Williams, 2010; Smith et al., 2017).

Motivational models of alcohol use (e.g., Cooper, Frone, Russell, \& Mudar, 1995; Cox \& Klinger, 1988) contend that one's motives for drinking are among the most proximal determinants of alcohol involvement (i.e., quantity and frequency of use, alcohol problems), and in general, individuals readily endorse both positive and negative reinforcement reasons for drinking (Kuntsche et al, 2005; 2014). Cooper and colleagues (1995) presented a model of four distinct but related categories of drinking motives; (1) experience enhancement motives whereby one consumes alcohol in order to promote positive affect, (2) coping motives where one drinks to relieve stress and negative affect, (3) social motives to facilitate social interaction, and (4) conformity motives where one drinks in order to avoid social rejection. Such motives are associated with distinct patterns of drinking with unique antecedents and consequences (Cox \& Klinger, 1988).

Although all forms of alcohol use are motivated to varying degrees, motivations stemming from the desire to alter one's internal emotional state (i.e., enhancement and coping motives) likely play a central role in explaining hazardous drinking patterns among those experiencing PTSD-related symptoms. Consistent with self-medication (Khantzian, 2003) and tension-reduction (Greeley \& Oei, 1999) theories, individuals who are motivated to drink to cope 
do so as a form of mood or affect regulation. These individuals are more likely to experience and report alcohol problems, irrespective of actual consumption (Cooper et al., 1995; Kuntsche et al, 2005). Ultimately, continued consumption of alcohol in this manner may exacerbate mental health symptoms, diminishing one's ability to effectively manage stressful situations in the future (Maisto, Carey, \& Bradizza, 1999). Conversely, desires to achieve a positive mental and affective state represent a core human motivation (Markus \& Wurf, 1987), and individuals are frequently motivated to consume alcohol as a means of facilitating or prolonging these positive experiences. As difficulty experiencing or expressing positive emotions remains a trademark symptom of PTSD (American Psychiatric Association, 2013), those with higher levels of PTSDrelated symptoms may be motivated to consume alcohol as a means of augmenting positive emotional experiences, as well as suppressing negative ones.

Researchers have only recently begun to investigate motivated drinking patterns among military populations (McDevitt-Murphy et al., 2015a; Miller, Pedersen, \& Marshall, 2017; Mohr, McCabe, Haverly, Hammer, \& Carlson, 2018; Simpson et al., 2014). For example, using a sample of veterans receiving a brief intervention for hazardous drinking, McDevitt-Murphy and colleagues (2015a) demonstrated that motivations for drinking could be distinguished by PTSD status, where those with PTSD reported significantly greater motives for drinking to cope with depression and anxiety relative to those without PTSD, and were more likely to experience greater consequences of their use. Others have recently uncovered evidence in line with selfmedication theories regarding alcohol involvement among U.S. service members, including Miller and colleagues (2017) who found evidence for mediation of coping motives in the PTSSalcohol relationship in a treatment sample. However, authors did not control for other alcohol use motives nor did they explore a variety or alcohol-related involvement variables. Further, in a 
previous analysis of the current dataset that focused on validating the multidimensional models of alcohol consumption, Mohr and colleagues (2018) revealed that coping motives mediated the relationship between psychological distress and alcohol problems. Although consistent with proposed relationships, Mohr and colleagues did not focus on PTSS.

Mixed evidence exists establishing a link between PTSD and enhancement motives. In contrast to coping motives, McDevitt-Murphy and colleagues (2015a) found those with and without PTSD did not differ in their endorsement of enhancement, social, or conformity motives, although enhancement motives were correlated with facets of PTSD (e.g., hyper arousal, impulse control). However, in their daily monitoring study of veterans and civilians with comorbid PTSD and alcohol use disorder participating in an experimental treatment study, Simpson and colleagues demonstrated that those low in enhancement motives increased their drinking $45 \%$ on days they experienced greater PTSD symptoms. Those higher in enhancement motives reported steady levels of drinking irrespective of their symptoms. Thus, although drinking motives in general have been linked with alcohol use and problems (see Cooper, Kuntsche, Levitt, Barber, \& Wolf, 2016 for review), coping and enhancement motives in particular may be the strongest determinants of alcohol involvement among service members suffering from PTSD and associated symptoms.

\section{Social Support and Health}

Interpersonal relationships and supports may attenuate or buffer PTSS, thereby reducing the motivation or need to drink. Among service members, such supportive factors aid in postdeployment recovery and functioning (Pietrzak et al., 2010; Russell et al., 2016, Wilcox, 2010), whereas lack of such support and feelings of isolation have been associated with greater reintegration difficulties following deployment (Sayer et al., 2010). The source of support, 
particularly from family and friends, is important to consider as these relationships may differentially influence health and well-being (Dakof \& Taylor, 1990; Uchino, Cacioppo, Kiecolt-Glaser, 1996). Pietrzak and colleagues (2010) showed that post-deployment support from one's family, friends, and community along with support and cohesion within one's military unit contributed to veteran resilience, and protected against PTSS and depressive symptoms. Thus, support and understanding from close others (e.g., family, close friends) may provide important outlets to offset or even prevent the development of mental health concerns.

\section{Present Study}

Individual motivations or reasons for drinking along with social supports represent two critical points of intervention for reducing problematic drinking among service members (Jacobson et al,, 2008; Norman, Schmied, \& Larson, 2014). These factors act as potential determinants of why service members are drinking, and can help identify under what conditions these relationships occur. Using baseline data from separated service members and current reservists participating in the Study for Employment Retention of Veterans (SERVe), the present study elaborated and extended prior research on alcohol involvement in the military in two fundamental ways: First by establishing whether one's endorsement of alcohol use motives help explain observed associations between PTSS and alcohol involvement. To achieve this, four parallel mediation models were tested where the four drinking motives were entered simultaneously. We specifically hypothesized the associations between PTSS and alcohol involvement would be indirect through coping and enhancement motives. We had no specific hypotheses with respect to social and conformity motives.

Next, we explored whether the indirect associations of PTSS on alcohol involvement through drinking motives were conditional upon one's perceived level of support from two 
sources: friends and family. That is, does the explanatory role of drinking motives on PTSSalcohol involvement associations change as a function of one's perceived level of support? As shown in Figure 1, the hypothesized models specified three pathways through which social support acted as a moderator, (1) the $a$ path from PTSS to motives, (2) the $b$ path from motives to alcohol involvement, and (3) the direct effect from PTSS to drinking outcomes ( $c$ path).

\section{$<$ INSERT FIGURE 1 HERE $>$}

\section{Method}

\section{Participants}

Sample and Procedure. Data were collected as part of the Study for Employment Retention of Veterans (SERVe), a randomized controlled trial designed to improve supports for separated service members and reservists in the workplace. Study team members recruited public and private sector organizations throughout the state of Oregon to participate in the training. Individuals who were employed at least part-time ( $\geq 20$ hours/week) at an organization participating in the intervention who were also either (a) serving in the National Guard or Reserve components (NG/R) or (b) had recently separated (no earlier that December 31, 2001) from the U.S. armed forces were eligible to participate in the study. After consenting to participate in the study, participants completed a comprehensive assessment during their nonwork time using Qualtrics, an online survey tool, and were offered a $\$ 25$ reloadable gift card for completing the survey (see Hammer et al., 2017 for further details).

A total of 509 service members participated in the study between April 2014 and November 2015. Ninety seven participants (19.1\%) were excluded from analyses because they reported no alcohol consumption during the past 30 days, and 14 were excluded due to missing demographic information. The final sample of 398 recent drinkers consisted of $83 \%$ men with an 
average age of 38.7 ( $S D=9.4$ years), a majority of which were married $(69.5 \%)$ and nonHispanic White (83.9\%). Most participants were recently separated from the military (80.7\% recently separated vs. $19.3 \%$ currently in the National Guard or Reserves) and had been in the military for an average of 12.4 years $(S D=8.3)$. Approximately half $(52 \%)$ of participants reported their most recent military component as being with the National Guard or Reserves.

\section{Measures}

PCL-M. A four-item version of the PTSD Checklist-Military version (PCL-M; Bliese et al., 2008) was used to assess PTSS. The PCL-M captures symptoms directly associated with experiences while serving in the military, and has been used in recent studies of military personnel (Cacioppo et al., 2016). Participants reported how bothered they had been in the past month by each symptom assessed using a 5-point Likert scale ( 1 not at all to 5 extremely) $(\alpha=$ .92). Items were summed to create a total symptomology score with a maximum possible score of 20. Probable PTSD was also calculated based on a score of $12+$ provided by Bliese and colleagues (2008).

Alcohol use. Alcohol use during the past month (30 days) was assessed via three items. Participants were shown a graphic that informed them of the definition of a "standard drink" (International Center for Alcohol Policies, 1998) and answered items about the number of (a) days they drank alcohol in the past month, (b) the typical or average number of drinks consumed, and (c) a binary (yes/no) variable indicating whether the participant engaged in heavy episodic drinking ( 5 or more drinks on an occasion for men, 4 or more drinks for women). Although all participants reported consuming alcohol on at least one occasion during the past month, 46 reported consuming an average number of 0 drinks. While such scores may approximate reality for individuals who typically do not drink, these scores were recoded to 0.5 to reflect a non-zero 
average level of consumption based on best-practice recommendations for handling multivariate outliers (Aguinis, Gottfredson, \& Joo, 2013). ${ }^{1}$

Alcohol problems. Alcohol problems were estimated based on the Alcohol Use Disorders Identification Test (AUDIT; Saunders, Aasland, Babor, De La Fuente, \& Grant, 1993). The 10-item AUDIT has been demonstrated as a reliable and valid assessment of high quantity and frequency of alcohol use, problematic use and dependence symptoms, and consequences of use in the past year (Allen, Litten, Fertig, \& Babor, 1997). To avoid multicollinearity concerns with alcohol use items, an adapted AUDIT score was computed that excluded items assessing alcohol consumption for all models based on standardized scoring procedures for items 4-10 with a maximum possible score of $30(\alpha=.79)$.

Drinking motives. Drinking motives were assessed using twelve items taken from the Drinking Motives Questionnaire-Short Form (DMQ-R-SF; Kuntsche \& Kuntsche, 2009). Participants were instructed to think about all the times they drank alcohol and report how often they drank for each reason using a 5-point Likert scale (1 almost never/never to 5 almost always/always). Alphas ( $\alpha$ ) ranged from .70 to .90 . Subscale scores were computed by taking the average of each subscale yielding maximum possible score of 5 for each subscale. For Confirmatory Factor Analysis and DMQ validation data in a military sample, please refer to Mohr and colleagues (2017).

Social support. Perceived social support from friends and family was assessed using a 14-item short form (Rice \& Longabaugh, 1996) adapted from the Perceived Social Support Scale (Procidano \& Heller, 1983); seven items represented support from friends $(\alpha=.92)$ and seven represented support from family $(\alpha=.81)$. The short form selects only comparable items across friend and family domains so that support from friends and family are similarly operationalized 
(and comparable). Response options were adapted for this study where participants reported their level of agreement with the provided statements using a 1 to 5 scale (Strongly disagree to strongly agree). Subscale scores were computed by taking the average of each subscale yielding maximum possible score of 5 for each subscale.

Covariates. All models controlled for participant age, race, gender, and current military status (active National Guard/Reserves vs. separated). Past research has shown younger individuals and men more strongly endorse motives for drinking and are more likely to consume alcohol to cope with stress (Maisto et al., 1999; Nolen-Hoeksema, 2004). Models predicting alcohol problems similarly controlled for quantity and frequency of alcohol use. Models also adjusted for the personality dimension of neuroticism $(\mathrm{N})$, which is characterized by high levels of negative emotionality (David \& Suls, 1999). Past research has linked N with alcohol involvement, but argued that this association can be explained in large part through the endorsement of drinking to cope motivations by those higher in N (Cooper, Agocha, \& Sheldon, 2000; Kuntsche, von Fischer, \& Gmel, 2008; Stewart \& Devine, 2000). Finally, given its strong association with PTSS and drinking, combat exposure (i.e., events and stressors one might experience while deployed) was included in statistical models as a covariate. Combat exposure was assessed using a 27 -item checklist where binary indicators of whether an event was experienced ( 1 Yes, $O$ No) were summed to generate the total number of exposures experienced on deployment (Cabrera et al., 2007; Guyker et al., 2013). Sixty five percent of participants reported multiple exposures $(M=6.46, S D=6.93)$, with knowing someone who had been seriously injured or killed $(52.1 \%)$ being the most commonly reported experiences.

\section{Analyses}


Parallel Multiple Mediator Model. The PROCESS macro was used to estimate four parallel indirect effect models using SPSS v22 (Hayes, 2013; model 4). In each model, the four drinking motives were entered simultaneously, so each indirect effect controls for the presence of the other mediators. One strength of PROCESS is the use of bias-corrected bootstrapping with resampling to estimate $95 \%$ confidence intervals for all indirect, total, and conditional indirect effects. Confidence intervals that do not contain a value of zero are considered statistically different from zero. In addition, PROCESS provides specific indirect effect contrasts which provide an empirical test of whether each indirect effect is statistically different from the others.

Conditional Indirect Effect Models. Next, the PROCESS macro was used to estimate eight conditional indirect effect models (Hayes, 2013; model 59) to determine the extent to which indirect effects of PTSS on alcohol involvement through the four drinking motives were contingent upon one's perceived level of support from friends and family. To examine the unique moderating role of support, models predicting support from family controlled for support from friends, and vice versa. In addition to conditional indirect effects, significant interaction terms were probed by examining simple effects for high $(+1 S D)$, moderate $(M)$ and low $(-1 S D)$ levels of social support (Aiken \& West, 1991). All variables involved in tests of moderation were centered on their respective means (Tabachnick \& Fidell, 2007).

To account for the number of outcomes tested and control for Type I error, we applied the Benjamini-Hochberg procedure to all models tested (Benjamini \& Hochberg, 1995). We report statistically significant findings and make note where changes occur due to the correction.

\section{Results}

\section{Descriptive Statistics}


Table 1 provides descriptive information and intercorrelations for study variables. Roughly $17 \%$ of participants met criteria for probable PTSD, and approximately $27 \%$ met criteria for problematic drinking based on an AUDIT score of 8 or greater. Additionally, $44 \%$ of participants reported at least one heavy drinking episode during the past 30 days.

\section{$<$ INSERT TABLE 1 HERE >}

\section{Indirect Effects}

Drinking Days. ${ }^{2}$ Results from all indirect effect models are displayed in Figure 2. In models predicting number of drinking days in the past month, PTSS was associated with greater coping ( $a=.30, p<.001)$ and enhancement motives $(a=.14, p=.02)$, but not social $(a=.12$, $p=.08)$, or conformity motives $(a=.01, p=.69)$. Coping $(b=2.65, p<.001)$ and enhancement motives $(b=1.92, p<.01)$ were significantly associated with higher number of past month drinking days. In addition, two significant indirect effects were observed for PTSS on drinking days through coping $(a b=.79 ; 95 \%$ BCCI: $[.37 ; 1.41])$ and enhancement motives $(a b=.28 ; 95 \%$ BCCI: $[.06 ; .67)$. Specific indirect effect contrasts revealed these effects were not significantly different from each other. Thus, a one point increase in PTSS was associated with a corresponding .79 increase in drinking days as a function of a greater endorsement of coping motives. A similar one point increase in PTSS was associated with a .28 increase in drinking days as a function of a greater endorsement of enhancement motives.

Average Drinks. Only coping $(b=.33, p<.01)$ and enhancement motives $(b=.31, p=.01)$ were associated with significantly higher drinks consumed on average. In addition, two significant indirect effects were observed for PTSS on average drinks consumed through coping $(a b=.10 ; 95 \%$ BCCI: $[.03 ; .21])$ and enhancement motives $(a b=.04 ; 95 \%$ BCCI: $[.01 ; .11)$. Specific indirect effect contrasts revealed these effects were not significantly different from each 
other. Thus, a one point increase in PTSS was associated with .10 increase in the number of drinks consumed on average as a function of a greater endorsement of coping motives. A similar one point increase in PTSS was associated with .04 increase in the number of drinks consumed on average as a function of a greater endorsement of enhancement motives.

Heavy Episodic Drinking. Only coping $(b=.75, p<.01)$ and enhancement motives $(b=.51, p<.01)$ were associated with significantly higher likelihood of having engaged in heavy episodic drinking during the past month. In addition, two significant indirect effects were observed for PTSS on average drinks consumed through coping ( $a b=.22$; 95\% BCCI: $[.09 ; .42])$ and enhancement motives $(a b=.07 ; 95 \%$ BCCI: $[.01 ; .18)$. Examination of specific indirect effect contrasts revealed these effects were not significantly different from each other. Indirect effects of social and conformity motives were not significantly different from zero. Thus, a one point increase in PTSS was associated with .22 higher odds of heavy drinking as a function of a greater endorsement of coping motives. A similar one point increase in PTSS was associated with .07 higher odds of heavy drinking as a function of a greater endorsement of enhancement motives.

Alcohol Problems. In models predicting alcohol problems, controlling for number of drinking days and average level of consumption, PTSS was associated with greater coping motives $(a=.22, p<.001)$, but not greater enhancement $(a=.06, p>.05)$, social $(a=.04, p>.05)$, or conformity motives $(a=-.00, p>.05)$. Coping motives, but not other drinking motives, were positively and significantly associated with alcohol problems $(b=1.31, p<.001)$. A significant indirect effect of PTSS on alcohol problems through coping motives was observed ( $a b=.29$; 95\% BCCI: $[.13 ; .32])$; all other indirect effects were not significantly different from zero. Thus, a one point increase in PTSS was associated with .29 unit increase in alcohol problems as a function of a greater endorsement of coping motives. 


\section{<INSERT FIGURE 2 HERE>}

\section{Conditional Indirect Effects ${ }^{3,4}$}

Perceived Support from Friends. Despite the lack of evidence of indirect effects of social and conformity motives, conditional process analyses were conducted for all four drinking motives given sufficient theoretical and empirical support for their importance (Preacher, Rucker, \& Hayes, 2007). As shown in Table 2, after the inclusion of perceived support from friends (FRIENDS) and its interaction with PTSS, PTSS remained positively related to coping motives in all models. Such motives, in turn, were associated with higher self-reported drinking days $(b=2.85, p<.001)$, average number of drinks consumed $(b=.41, p<.001)$, and alcohol problems $(b=1.35, p<.001)$. In addition, those endorsing greater coping motives were at significantly higher odds of heavy episodic drinking $(b=.83, p<.001)$. Adjusting for other motives, there was a significant conditional indirect effect for PTSS on average number of drinks consumed and alcohol problems through coping motives. Specifically, the indirect effects were significantly different from zero at low ( $a b=.17$ and .30 respectively) and average levels of FRIENDS ( $a b=.11$ and .25 respectively), but not at high levels of FRIENDS ( $a b=.06$ and .18 respectively). Indirect effects of PTSS on number of drinking days and likelihood of heavy episodic drinking through coping motives remained significantly different from zero irrespective of one's level of FRIENDS.

As shown in Table 3, PTSS was positively related to enhancement motives in all consumption models (i.e., number of drinking days, average number of drinks consumed, likelihood of heavy episodic drinking; $p s<.05)$. However, when controlling for level of consumption, PTSS was not significantly associated with enhancement motives $(a=.05, p=.42)$. Such motives, in turn, were associated with higher self-reported drinking days $(b=2.00, p<.01)$, 
average number of drinks consumed $(b=.28, p<.05)$, and higher odds of heavy episodic drinking $(b=.51, p<.01)$. Consistent with this evidence, adjusting for other motives, there was a significant conditional indirect effect of enhancement motives on all three consumption variables, but not alcohol problems. The indirect effects of PTSS on consumption through enhancement motives was significant only at average levels of FRIENDS ( $a b=.26, .04$, and .07 respectively). However, when applying the Benjamini-Hochberg procedure (Benjamini \& Hochberg, 1995), the conditional indirect effect for average number of drinks consumed was no longer significant due to attenuated association between enhancement motives and average number of drinks. Lastly, a significant interaction was observed between enhancement motives and FRIENDS predicting average level of consumption $(b=.38, p<.01)$ (see Figure 3) Simple slopes tests revealed the positive association between enhancement motives and average level of consumption to be significant for those perceiving average $(b=.28, t(387)=2.33, p<.05)$ and high levels of FRIENDS $(b=.58, t(387)=3.60, p<.001)$. Simple slopes were negative and not significant at low levels of FRIENDS $(b=-.03, t(387)=-.19, p=.85)$.

No conditional direct or indirect effects were observed for social or conformity motives. Surprisingly, a significant interaction was observed between conformity motives and FRIENDS predicting alcohol problems $(b=-.94, p<.05)$, although simple slopes at low $(-1 \mathrm{SD})$, average, and high levels (+1 SD) of FRIENDS were not significant. This effect was no longer significant after applying the Benjamini-Hochberg adjustment.

\section{$<$ INSERT FIGURE 3 ABOUT HERE>}

Perceived Support from Family. Similar to the previous models, analyses examining the moderating role of perceived support from family (FAMILY) revealed PTSS to be positively and significantly related to coping motives. Such motives, in turn, were associated with higher past 
year alcohol problems $(b=1.33, p<.001)$, self-reported drinking days $(b=2.79, p<.001)$, and average number of drinks consumed, on average $(b=.46, p<.001)$. Finally, those endorsing greater coping motives were at significantly higher odds of past month heavy episodic drinking ( $b=.89, p<.001)$. Adjusting for other motives, there was a significant conditional indirect effect for PTSS on the average number of drinks consumed. Unlike previous models, the indirect effect was significantly different from zero at average $(a b=.13$; 95\% BCCI: $[.05 ; .25])$ and high levels of FAMILY $(a b=.18 ; 95 \%$ BCCI: $[.05 ; .37])$, but not at low levels of FAMILY support ( $a b=$ $.08 ; 95 \%$ BCCI: $[-.00 ; .24])$. No other conditional indirect or direct effects were observed for coping motives (see Table 2).

The effects of PTSS on enhancement motives, and enhancement motives on consumption variables and alcohol problems were unchanged when examining the moderating role of FAMILY (see Table 3). Moreover, with the exception of drinking days, conditional indirect effects mirrored models examining FRIENDS. Specifically, after adjusting for other motives, there was a significant conditional indirect effect for PTSS on all three consumption variables through enhancement motives but not alcohol problems. While the indirect effect of PTSS on drinking days through enhancement motives was significant at low $(a b=.33 ; 95 \%$ BCCI: [.00; $1.01])$ and average levels of FAMILY ( $a b=.26 ; 95 \%$ BCCI: $[.04 ; .64])$, indirect effects for average number of drinks consumed and heavy episodic drinking via enhancement motives were significant only at average levels of FAMILY ( $a b=.05$ and .08 respectively). No other conditional direct or indirect effects were observed for social or conformity motives.

$<$ INSERT TABLES $2 \& 3$ HERE $>$

\section{Discussion}


Alcohol misuse and symptoms of posttraumatic stress disorder not only have strong implications for combat readiness and performance among those actively serving in the military, but also present significant challenges as service members alternate between military and civilian roles, or reintegrate into their roles as civilians post-separation (Adler et al., 2011; Fisher et al., 2000). It remains imperative to examine the mechanisms which link mental health symptoms and alcohol use, as well as the conditions under which they co-occur. The present study represents an important step toward an integrated understanding of PTSS and alcohol use among military personnel, and demonstrates alcohol use motives as potential mechanisms through which PTSS may influence drinking behavior and consequences. Among a large sample of separated service members and reservists, as well as actively drilling $\mathrm{NG} / \mathrm{R}$ who reported drinking during the past month, alcohol use motivations stemming from a desire to alter one's internal emotional state appear to be stronger correlates of drinking behavior and problems relative to motives derived from external sources which fulfill more affiliative needs (e.g., to facilitate social interactions or to conform to situational norms). Moreover, social influences in the form of perceived support from friends and family are differentially related to both the reasons why one might drink and one's related drinking behavior.

\section{Conditional Indirect Effect of Coping Motives}

Results revealed that when adjusting for other drinking motives, associations between PTSS and average quantity and frequency of use, heavy episodic drinking, and alcohol problems were indirect through coping motives. That is, higher levels of PTSS were associated with greater endorsement of coping motives, which were in turn associated with higher levels of alcohol involvement. Despite replication of this common finding, evidence supporting these pathways among members of the US military is sparse. To date, we are aware of one other study 
to examine coping motives as a mediator of PTSS and alcohol involvement (e.g., Miller et al., 2017). However, their study did not adjust for other drinking motivations and did not examine motives as mediators of alcohol consumption. Our study extended this work by addressing these limitations and further exploring the conditional nature of these associations.

Although conditional indirect effect hypotheses were not supported for some alcohol use outcomes in this study, consistent with the buffering hypothesis (Cohen \& Wills, 1985), the indirect effects of PTSS on alcohol problems and average level of consumption through coping motives were conditional on one's level of perceived support from friends. That is, the indirect effects became weaker as support increased, and were nonsignificant among those perceiving higher (+ $1 \mathrm{SD}$ ) levels of support. It may be that when experiencing high levels of PTSS symptoms, those perceiving high support from their close friends are utilizing alternative coping strategies or are engaging in activities with close friends that do not involve drinking. That perceived friend support has this apparent benefit in attenuating this pathway is particularly relevant given the strong links between coping motives and alcohol problems established in the literature (Cooper et al., 2016; Kuntsche et al., 2005).

In contrast, only the indirect effect of PTSS on average level of consumption was observed for perceived support from family. Specifically, the indirect effect was significant among those at average and higher (+1 SD) levels of family support, but not at lower (-1 SD) levels. Interestingly, with the exception of number of past month drinking days, the size of indirect effects for alcohol problems, average number of drinks consumed, and heavy episodic drinking became stronger as family support increased. Such results run counter to expectations given the breadth of evidence suggesting health benefits of social support (McCreary \& Sadava, 1998; Mohr, Averna, Kenny, \& Del Boca, 2001). Yet attempts at providing support are not 
uniformly effective, and may promote negative health behaviors or exacerbate mental health symptoms (Cohen \& LeMay, 2007; Gros et al, 2016; Russell et al., 2016). Gros and colleagues (2016) found evidence that perceptions of support were positively related to number of drinking days among service members seeking treatment for comorbid PTSD and substance use disorders. They partially attributed this effect to service members seeking support and drinking as a means of accruing social rewards and resources. Consistent with this view, it may be that for some, particularly those who are motivated to drink to alleviate stress, alcohol use and support processes may be confounded. Future research is needed to further delineate this process.

\section{Conditional Indirect Effect of Enhancement Motives}

The associations between PTSS and alcohol consumption (average quantity and frequency of use, and heavy episodic drinking) were also indirect through enhancement motives. Although PTSS and coping motives are perhaps more intuitively linked through negative emotionality, individuals with PTSD or experiencing PTSD-related symptoms may have difficulty experiencing or expressing positive emotions (APA, 2013), and may be motivated to consume alcohol as a means of generating positive experiences. Consistent with prior research, no indirect effect of enhancement motives was found when predicting alcohol problems. Such motives may be associated with problems only via high levels of consumption (e.g., Cooper et al., 1995).

With the exception of number of drinking days, indirect effects of PTSS on alcohol consumption were significant only for those at average levels of support from friends and family. Among those perceiving average levels of support from friends and family, individuals who experienced greater PTSS over the past month reported greater motivation to consume alcohol as a means of experiencing or promoting positive emotion, which in turn was associated with 
greater and more frequent alcohol consumption. Although somewhat counterintuitive that the indirect effects were nonsignificant at both low and high levels of support. It may be that those lower in perceived support were more isolated from their peers and family, and were thus more motivated to drink for reasons other than to enhance positive emotion (e.g., to cope). Conversely, those perceiving higher levels of support were likely more connected and engaged with their support network, and thus have other means and methods of obtaining positive interpersonal rewards. Additional research is needed, particularly with respect to enhancement motives, to determine what role social relationships play in promoting or inhibiting alcohol involvement in response to PTSS.

Additionally, perceptions of support from one's friends moderated associations between enhancement motives and average level of consumption. At lower levels of enhancement motives, those perceiving higher levels of support from friends reported the lowest levels of drinking. This effect crossed over, where at higher endorsement of enhancement motives, drinking was highest among those perceiving higher levels of support from friends. As argued above, this evidence is not meant to suggest that support from friends ubiquitously promotes poor health behavior. In some situations, it is possible, if not plausible that service members seek out close friends for companionship, camaraderie, and to boost positive emotionality, and that these activities may include drinking. Importantly, these effects occurred independently of social and coping motivations for drinking, and neither enhancement motives nor perceived support from friends or family were directly related to alcohol problems. To the extent that close friends are attuned and responsive to the service members, drinking with close others may reflect a less problematic pattern of consumption, and may dampen the impact of certain stressors on negative mood (Armeli et al., 2003). Future research is needed to examine the nature of these 
relationships, and researchers should continue to distinguish sources and type of support being provided, as substantive differences may arise.

\section{Limitations and Future Directions}

As the current study is cross-sectional in nature, causality and directionality of effects cannot be established. Although results from the present study are consistent with cross-sectional and longitudinal evidence suggesting alcohol motivations act as proximal mechanisms through which mental health symptoms are related to alcohol involvement (Angkaw et al., 2015; Cooper et al, 2016; Hien et al., 2010; Miller et al., 2017; Simpson et al., 2014), alcohol use and problems may also contribute to or exacerbate existing PTSD symptomology (McFarlane et al., 2009). Caution should be exercised when interpreting study findings in lieu of this limitation, and future research should examine these relationships longitudinally to determine whether alcohol involvement is associated with later changes in posttraumatic stress symptoms.

The present study may also have limited generalizability when compared to others comprised exclusively of actively serving or separated military service members. Importantly, active and separated service members in our sample did not differ in terms of prevalence of likely PTSD or alcohol problems, or alcohol involvement. The present community sample of separated service members as well as currently serving members of the National Guard or Reserves, reinforces the applicability of drinking motives for understanding alcohol involvement among members of the US Armed Forces. The extant literature exploring alcohol and substance use motivations among military personnel has been almost exclusively comprised of studies of veterans from primary care settings (e.g., McDevitt-Murphy et al, 2015a), or receiving some form of intervention (Miller et al., 2017; Simpson et al., 2014). By adopting a more inclusive recruitment approach beyond those presenting with pathologic symptoms or seeking primary 
care, our study design addresses concerns raised by authors such as Sayer and colleagues (2010) who argued that current research practices have often neglected service members from branches other than the Army, particularly NGRs.

\section{Opportunities for Intervention}

Roughly $40 \%$ of service members report experiencing one or more mental health problems following deployment. However, these rates may underestimate the true prevalence when one considers stigma surrounding mental illness in the military (see Britt, 2007). Evidence indicates service members are finding alternative means of coping with deployment stress, oftentimes through increases in alcohol use. Thus, specific, tailored interventions designed to fit an individual's needs and circumstances are required.

As drinking motives represent a "final pathway" (Cox \& Klinger, 1988) through which emotional experiences and mental health concerns can influence alcohol involvement, preexisting programs and screening efforts may be bolstered by increasing attention to individual motivations, beliefs, and cognitions surrounding alcohol use (Miller \& Rollnick, 1991, P.M. Miller et al., 2014; Wurdak, Wolstein, \& Kuntsche, 2016). Incorporation of this perspective could assist service members in identifying potential "triggers" for their alcohol use behavior, thus providing a sense of agency and control, reducing the likelihood of drinking as a form of emotional regulation or symptom management, and identifying alternative methods of experiencing positive emotions and enjoyment. In addition, Cacioppo and colleagues (2015) argued the promotion of "social resilience," the ability to foster and maintain positive relationships, and to grow and recover from stress, as among the focal priorities for assisting service members in reintegrating into civilian roles. As such, improved practices with an 
emphasis on relationship building for service members and their families would likely improve reintegration outcomes greatly.

\section{Conclusion}

The present study suggests that among recent drinkers, motivations to alter one's negative and positive emotional state are useful in explaining well-established associations between PTSS and alcohol involvement observed in military populations. Such motives have tremendous utility for intervention efforts designed to reduce harmful drinking behavior among service members. Moreover, this study further reinforces the importance of social relationships in influencing health behavior among service members. Future research should continue to address contextual factors which influence support effectiveness, including the source and type of support. 


\section{Footnotes}

${ }^{1}$ Results did not differ between models which included values of 0 for average number of drinks consumed and those with recoded 0.5 values.

${ }^{2} A$ pathways from PTSS to drinking motives were identical for models predicting number of drinking days, average number of drinks consumed, and likelihood of engaging in heavy episodic drinking. Models predicting alcohol problems controlled for both number of drinking days and heavy episodic drinking.

${ }^{3}$ Alcohol problem models were re-examined using the full AUDIT. The internal consistency of the full AUDIT was slightly higher than the adapted version $(\alpha=.82$ and .79 respectively). Overall, results did not differ from those presented in the manuscript. For models examining the conditional influence of perceived support from friends, coping motives were associated with higher AUDIT scores $(b=1.50, \mathrm{p}<.001)$, and there was a significant conditional indirect effect for PTSS on AUDIT scores through coping motives where the indirect effect was significantly different from zero at low $(a b=.34)$ and average levels of friend support $(a b=.28)$, but not at high levels of friend support $(a b=.20)$. For models examining the conditional influence of perceived support from family, coping motives were again associated with higher AUDIT scores $(b=1.43, \mathrm{p}<.001)$, but the indirect effect of PTSS on AUDIT scores through coping motives was not conditional upon one's perceived level of support from family.

${ }^{4}$ Effects of study covariates (age, race, gender, military status, neuroticism, and combat exposure) are not reported. In all conditional indirect effect models, only age was associated with number of drinking days and likelihood of heavy episodic drinking, whereas gender was associated with average number of drinks consumed. Younger participants were more likely to engage in heavy episodic drinking during the past month $(b=-.04, \mathrm{z}=-2.79, p<.01)$, whereas 
older participants reported more drinking days, on average $(b=.16, t(379)=3.57, p<.001)$. Men consumed significantly higher levels of alcohol, on average $(b=-.22, t(379)=-2.03, p<.05)$, although when applying the Benjamini-Hochberg procedure, the gender difference was no longer significant.

Declaration of Interest: The authors report no conflicts of interest. The authors alone are responsible for the content and writing of the paper. 


\section{References}

Adler, D. A, Possemato, K., Mavandadi, S., Lerner, D., Chang, H., Klaus, J., ... Oslin, D. W. (2011). Psychiatric status and work performance of veterans of Operations Enduring Freedom and Iraqi Freedom. Psychiatric Services, 62(1), 39-46.

Aiken, L. S., \& West, S. G. (1991). Multiple regression: Testing and interpreting interactions. Newbury Park, CA: Sage.

Aguinis, H., Gottfredson, R. K., \& Joo, H. (2013). Best-practice recommendations for defining, identifying, and handling outliers. Organizational Research Methods, 16(2), 270-301.

Allen, J. P., Litten, R. Z., Fertig, J. B., \& Babor, T. (1997). A review of research on the Alcohol Use Disorders Identification Test (AUDIT). Alcoholism, Clinical and Experimental Research, 21(4), 613-619

American Psychiatric Association (APA). (2013) Diagnostic and statistical manual of mental disorders, (5th ed.). Washington, DC: Author.

Angkaw, A.C., Haller, M., Pittman, J.O.E., Nunnink, S.E., Norman, S.B., .. \& Baker, D.G. (2015). Alcohol-related consequences mediating PTSD symptoms and mental healthrelated quality of life in OEF/OIF combat veterans. Military Medicine, 180, 670-674.

Benjamini, Y., \& Hochberg, Y. (1995). Controlling the false discovery rate: A practical and powerful approach to multiple testing. Journal of the Royal Statistical Society. Series B, 57, 289-300.

Bliese, P.D. (2006). Social climates: Drivers of soldier well-being and resilience. In A.B. Adler, C.A. Castro, \& T.W. Britt (Eds.) Military life: The Psychology of Serving in Peace and Combat: Vol. 2. Operational Stress (pp. 213-234). Westport, CT: Praeger. 
Bliese, P. D., Wright, K. M., Adler, A. B., Cabrera, O., Castro, C. A., \& Hoge, C. W. (2008). Validating the primary care posttraumatic stress disorder screen and the posttraumatic stress disorder checklist with soldiers returning from combat. Journal of Consulting and Clinical Psychology, 76(2), 272-81.

Bray, R. M., Brown, J. M., \& Williams, J. (2013). Trends in binge and heavy drinking, alcoholrelated problems, and combat exposure in the U.S. Military. Substance Use \& Misuse, 48, $799-810$.

Britt, T. W., Greene-Shortridge, T. M., \& Castro, C. A. (2007). The stigma of mental health problems in the military. Military Medicine, 172(2), 157-61.

Brown, P. J., \& Wolfe, J. (1994). Substance abuse and post-traumatic stress disorder comorbidity. Drug and Alcohol Dependence 35, 51-59.

Cabrera, O. A., Hoge, C. W., Bliese, P. D., Castro, C. A., \& Messer, S. C. (2007). Childhood adversity and combat as predictors of depression and post-traumatic stress in deployed troops. American Journal of Preventive Medicine, 33, 77-82.

Cacioppo, J.T., Adler, A.B., Lester, P.B., McGurk, D., Thomas, J.L., Chen, H, \& Cacioppo, S. (2015). Building social resilience in soldiers: A double dissociative randomized controlled study. Journal of Personality and Social Psychology, 109, 90-105.

Cacioppo, J.T., Cacioppo, S., Adler, A.B., Lester, P.B., McGurk, D., Thomas, J.L., \& Chen, H.Y. (2016). The cultural context of loneliness: Risk factors in active duty soldiers. Journal of Social and Clinical Psychology, 35, 865-882.

Cohen, S., \& Lemay, E. P. (2007). Why would social networks be linked to affect and health practices? Health Psychology, 26(4), 410-417. 
Cohen, S., \& Wills, T. A. (1985). Stress, social support, and the buffering hypothesis. Psychological Bulletin, 98(2), 310-357.

Cooper, M. L. (1994). Motivations for alcohol use among adolescents: Development and validation of a four-factor model. Psychological Assessment, 6, 117-128.

Cooper, M. L., Agocha, V. B., \& Sheldon, M. S. (2000). A motivation perspective on risky behaviors: The role of personality and affect regulatory processes. Journal of Personality, 68, 1059-1088.

Cooper, M. L., Frone, M. R., Russell, M., \& Mudar, P. (1995). Drinking to regulate positive and negative emotions: A motivational model of alcohol use. Journal of Personality and Social Psychology, 69, 990-1005.

Cooper, M. L., Kuntsche, E., Levitt, A., Barber, L., \& Wolf, S. (2016). A motivational perspective on substance use: Review of theory and research. In K. J. Sher (Ed.), Oxford Handbook of Substance Use Disorders. New York, NY: Oxford University Press. doi:10.1093/oxfordhb/9780199381678.013.017

Cooper, M. L., Russell, M., Skinner, J. B., Frone, M. R., \& Mudar, P. (1992). Stress and alcohol use: Moderating effects of gender, coping, and alcohol expectancies. Journal of Abnormal Psychology, 101, 139- 152.

Cox, M., \& Klinger, E. (1988). A motivational model of alcohol use. Journal of Abnormal Psychology, 97, 168-180.

Dakof, G. A, \& Taylor, S. E. (1990). Victims' perceptions of social support: what is helpful from whom? Journal of Personality and Social Psychology, 58(1), 80-89.

David, J. P., \& Suls, J. (1999). Coping efforts in daily life: Role of big five traits and problems appraisals. Journal of Personality, 67, 265-294. 
Fisher, C. A., Hoffman, K. J., Austin-Lane, J., \& Kao, T. (2000). The relationship between heavy alcohol use and work productivity loss in active duty military personnel: A secondary analysis of the 1995 Department of Defense Worldwide Survey. Military Medicine, 5, $355-361$.

Foa, E.B., \& Williams, M.T. (2010). Methodology of a randomize double-blind clinical trial for comorbid posttraumatic stress disorder and alcohol dependence. Mental Health and Substance Use: Dual Diagnosis, 3, 131-147.

Fulton, J. J., Calhoun, P. S., Wagner, H. R., Schry, A. R., Hair, L. P., Feeling, N., . . Beckham, J. C. (2015). The prevalence of posttraumatic stress disorder in Operation Enduring Freedom/Operation Iraqi Freedom (OEF/OIF) Veterans: a meta-analysis. Journal of Anxiety Disorders, 31, 98-107. doi:10.1016/j.janxdis.2015.02.003

Gaher, R. M., Simons, J. S., Hahn, A. M., Hofman, N. L., Hansen, J., \& Buchkoski, J. (2014). An Experience Sampling Study of PTSD and Alcohol-Related Problems. Psychology of Addictive Behaviors, 28, 1013-1025.

Greeley, J., \& Oei, T. (1999). Alcohol and tension reduction. In K. E. Leonard \& H. T. Blane (Eds.), Psychological theories of drinking and alcoholism (2nd ed.) (pp. 14-53). New York, NY: Guilford Press.

Griffith, J. (2010). Citizens coping as Soldiers: A review of deployment stress symptoms among Reservists. Military Psychology, 22, 176-206.

Gros, D.F., Flanagan, J.C., Korte, K.J., Mills, A.C., Brady, K.T., \& Back, S.E. (2016). Relations among social support, PTSD symptoms, and substance use in veterans. Psychology of Addictive Behaviors. doi: http://dx.doi.org/10.1037/adb0000205 
Guyker, W. M., Donnelly, K., Donnelly, J. P., Dunnam, M., Warner, G. C., Kittleson, J., Bradshaw, C. B., ... Meier, S. T. (2013). Dimensionality, reliability, and validity of the Combat Experiences Scale. Military Medicine, 178, 377-384.

Hammer, L. B., Wan, W. H., Brockwood, K. J., Mohr, C. D., \& Carlson, K. F. (2017; Under review). Military, work, and health characteristics of veterans and reservists from the Study for Employment Retention of Veterans (SERVe).

Hayes, A. F. (2013). Introduction to mediation, moderation, and conditional process analysis: A regression-based approach. New York, NY: The Guilford Press.

Hoge, C. W., Terhakopian, A., Castro, C. A., Messer, S. C., \& Engel, C. C. (2007). Association of posttraumatic stress disorder with somatic symptoms, health care visits, and absenteeism among Iraq war veterans. American Journal of Psychiatry, 164(1), 150-153.

International Center for Alcohol Policies. (1998). What is a standard drink? Retrieved from http///www.icap.org/portals/0/download/all_pdfs/ICAP_Reports_English/report5.pdf.

IOM (Institute of Medicine). (2012). Substance use disorders in the U.S. Armed Forces. Washington, DC: The National Academies Press.

IOM (Institute of Medicine). (2014). Treatment for posttraumatic stress disorder in military and veteran populations: Final assessment. Washington, DC: The National Academies Press.

Jacobson, I. G., Ryan, M. A. K., Hooper, T. I., Smith, T. C., Amoroso, P. J., Boyko, E. J., ... Bell, N. S. (2008). Alcohol Use and Alcohol-Related Problems Before and After Military Combat Deployment. JAMA, 300(6), 663-675.

King, D. W., King, L. A, Foy, D. W., Keane, T. M., \& Fairbank, J. A. (1999). Posttraumatic stress disorder in a national sample of female and male Vietnam veterans: risk factors, 
war-zone stressors, and resilience-recovery variables. Journal of Abnormal Psychology, 108(1), 164-170.

Kuntsche, E., Knibbe, R., Gmel, G., \& Engels, R. (2005). Why do young people drink? A review of drinking motives. Clinical Psychology Review, 25(7), 841-861.

Kuntsche, E., \& Kuntsche, S. (2009). Development and validation of the Drinking Motive Questionnaire Revised Short Form (DMQ-R SF). Journal of Clinical Child and Adolescent Psychology, 38(6), 899-908.

Kuntsche, E., von Fischer, M., \& Gmel, G. (2008). Personality factors and alcohol use: A mediator analysis of drinking motives. Personality and Individual Differences, 45, 796-800.

Lehavot, K., Stappenbeck, C. A, Luterek, J. A, Kaysen, D., \& Simpson, T. L. (2014). Gender differences in relationships among PTSD severity, drinking motives, and alcohol use in a comorbid alcohol dependence and PTSD sample. Psychology of Addictive Behaviors, $28(1), 42-52$.

Maisto, S. A, Carey, K. B., \& Bradizza, C. M. (1999). Social Learning Theory. In K. E. Leonard \& H. T. Blane (Eds.), Psychological theories of drinking and alcoholism (2nd ed.) (pp. 106-163). New York, NY: Guilford Press.

Markus, H., \& Wurf, E. (1987). The dynamic self-concept: A social psychological perspective. Annual Review of Psychology, 38, 299-337.

McCreary, D. R., \& Sadava, S. W. (1998). Stress, drinking, and the adverse consequences of drinking in two samples of young adults. Psychology of Addictive Behaviors, 12, 247261.

McDevitt-Murphy, M. E., Williams, J. L., Bracken, K. L., Fields, J. A., Monahan, C. J., \& Murphy, J. G. (2010). PTSD symptoms, hazardous drinking, and health functioning 
among U.S. OEF/OIF veterans presenting to primary care. Journal of Traumatic Stress, 23, 108-111.

McDevitt-Murphy, M. E., Fields, J. A., Monahan, C. J., \& Bracken, K. L. (2015a). Drinking motives among heavy-drinking veterans with and without posttraumatic stress disorder. Addiction Research \& Theory, 23, 148-155.

McDevitt-Murphy, M. E., Williams, J. L., Murphy, J. G., Monahan, C. J., \& Bracken-Miller, K. L. (2015b). Brief intervention to reduce hazardous drinking and enhance coping among OEF/OIF/OND veterans. Professional Psychology: Research and practice, 46, 83-89.

McFarlane, A.C., Brown, D., Bryant, R.A., O’Donnell, M., Silove, D., Creamer, M., \& Horsley, K. (2009). A longitudinal analysis of alcohol consumption and the risk of posttraumatic symptoms. Journal of Affective Disorders, 118, 166-172.

Metrik, J., Jackson, K., Bassett, S.S., Zvolensky, M.J., Seal, K., \& Borsari, B. (2016). The mediating roles of coping, sleep, and anxiety motives in cannabis use among returning veterans with PTSD and MDD. Psychology of Addictive Behaviors. http://dx.doi.org/10.1037/adb0000210

Miller, S.M., Pedersen, E.R., \& Marshall, G.N. (2017). Combat experience and problemdrinking in veterans: Exploring the roles of PTSD, coping motives, and perceived stigma. Addictive Behaviors 66, 90-95.

Milliken, C. S., Auchterlonie, J. L., \& Hoge, C. W. (2007). Longitudinal assessment of mental health problems among active and reserve component soldiers returning from the Iraq war. JAMA : The Journal of the American Medical Association, 298(18), 2141-2148. 
Mohr, C. D., Averna, S., Kenny, D. a, \& Del Boca, F. K. (2001). "Getting by (or getting high) with a little help from my friends": an examination of adult alcoholics' friendships. Journal of Studies on Alcohol, 62, 637-645.

Mohr, C., McCabe, C.T., Haverly, S., Hammer, L., \& Carlson, K. (2017). Drinking motives and alcohol use: The SERVe study of U.S. current and former service members. Journal of Studies on Alcohol and Drugs, 79, 79-87.

Nolen-Hoeksema, S. (2004). Gender differences in risk factors and consequences for alcohol use and problems. Clinical Psychology Review, 24(8), 981-1010.

Norman, S. B., Schmied, E., \& Larson, G. E. (2014). Predictors of Continued Problem Drinking and Substance Use Following Military Discharge. Journal of Studies on Alcohol and Drugs, 75, 557-566.

Pietrzak, R. H., Johnson, D. C., Goldstein, M. B., Malley, J. C., Rivers, A. J., Morgan, C. A., \& Southwick, S. M. (2010). Psychosocial buffers of traumatic stress, depressive symptoms, and psychosocial difficulties in veterans of Operations Enduring Freedom and Iraqi Freedom: The role of resilience, unit support, and postdeployment social support. Journal of Affective Disorders, 120, 188-192.

Possemato, K., Maisto, S. A, Wade, M., Barrie, K., McKenzie, S., Lantinga, L. J., \& Ouimette, P. (2015). Ecological Momentary Assessment of PTSD symptoms and alcohol use in combat veterans. Psychology of Addictive Behaviors, 29, 894-905.

Procidano, M.E., \& Heller, K. (1983). Measures of perceived social support from friends and family: Three validation studies. American Journal of Community Psychology, 11, 1-24.

Ramchand, R., Rudavsky, R., Grant, S., Tanielian, T., \& Jaycox, L. (2015). Prevalence of, Risk Factors for, and Consequences of Posttraumatic Stress Disorder and Other Mental Health 
Problems in Military Populations Deployed to Iraq and Afghanistan. Current Psychiatry Reports, 17, 37 .

Rice, C., \& Longabaugh, R. (1996). Measuring general social support in alcoholic patients: Short forms for perceived social support. Psychology of Addictive Behaviors, 10(2), 104-114.

Russell, D. W., Benedek, D. M., Naifeh, J. A., Fullerton, C. S., Benevides, N., Ursano, R. J., ... Cacioppo, J. T. (2016). Social Support and Mental Health Outcomes Among U.S. Army Special Operations Personnel. Military Psychology. doi: 10.1037/mil0000114

Russell, D. W., Russell, C. A., Riviere, L. A, Thomas, J. L., Wilk, J. E., \& Bliese, P. D. (2014). Changes in alcohol use after traumatic experiences: the impact of combat on Army National Guardsmen. Drug and Alcohol Dependence, 139, 47-52.

Saunders, J., Aasland, O., Babor, T., De La Fuente, J., \& Grant, M. (1993). Development of the Alcohol Use Disorders Test (AUDIT): WHO collaborative project on early detection of persons with harmful alcohol consumption-II. Addiction, 88, 791-804.

Sayer, N. A., Noorbaloochi, S., Frazier, P., Carlson, K., Gravely, A., \& Murdoch, M. (2010). Reintegration Problems and Treatment Interests Among Iraq and Afghanistan Combat Veterans Receiving VA Medical Care. Psychiatric Services, 61(6), 589-597.

Sayette, M. A. (2000). Does drinking reduce stress? Alcohol Research \& Health, 23, 250-255.

Simpson, T. L., Stappenbeck, C. A, Luterek, J. A, Lehavot, K., \& Kaysen, D. L. (2014).

Drinking motives moderate daily relationships between PTSD symptoms and alcohol use. Journal of Abnormal Psychology, 123(1), 237- 247. 
Smith, B.N., Taverna, E.C., Fox, A.B., Schnurr, P.P., Matteo, R.A., \& Vogt, D. (2017). The role of PTSD, depression, and alcohol misuse symptom severity in linking deployment stressor exposure and post-military work and family outcomes in male and female veterans. Clinical Psychological Science. DOI: https://doi.org/10.1177/2167702617705672

Substance Abuse and Mental Health Services Administration (SAMHSA)(2014). National Survey on Drug Use and Health (NSDUH). Table 2.46B-Alcohol use, binge alcohol use, and heavy alcohol use in the past month among persons aged 18 or older, by demographic characteristics: Percentages, 2013 and 2014. Available at: http:/www. samhsa.gov/data/sites/default/files/NSDUH-DetTabs2014/NSDUHDetTabs2014.htm\#tab2-46b

Tabachnick, B.G., \& Fidell, L.S. (2007). Using Multivariate Statistics, $5^{\text {th }}$ ed. Boston: Pearson. Tanielian, T., and L. H. Jaycox (Eds.). 2008. Invisible wounds of war: Psychological and cognitive injuries, their consequences, and services to assist recovery. Santa Monica, CA: RAND Corporation.

Thomas, J. L., Wilk, J. E., Riviere, L. A., Mcgurk, D., Castro, C. A., \& Hoge, C. W. (2010). Prevalence of Mental Health Problems and Functional Impairment Among Active Component and National Guard Soldiers 3 and 12 Months Following Combat in Iraq. Archives of General Psychiatry, 67(6), 614-623.

Uchino, B., Cacioppo, J., Kiecolt-Glaser, J., \& Anonymous. (1996). The relationship between social support and physiological processes: A review with emphasis on underlying mechanisms and implications for health. Psychological Bulletin, 119(3), 488-531. 
Wilcox, S. (2010). Social relationships and PTSD symptomatology in combat veterans. Psychological Trauma: Theory, Research, Practice, and Policy, 2(3), 175-182.

Wilk, J. E., Bliese, P. D., Kim, P. Y., Thomas, J. L., McGurk, D., \& Hoge, C. W. (2010). Relationship of combat experiences to alcohol misuse among U.S. soldiers returning from the Iraq war. Drug and Alcohol Dependence, 108, 115-121.

Wurdak, M., Wolstein, J., \& Kuntsche, E. (2016). Effectiveness of a drinking-motive-tailored emergency-room intervention among adolescents admitted to hospital due to acute alcohol intoxication - A randomized controlled trial. Preventive Medicine Reports, 3, 83-89. 


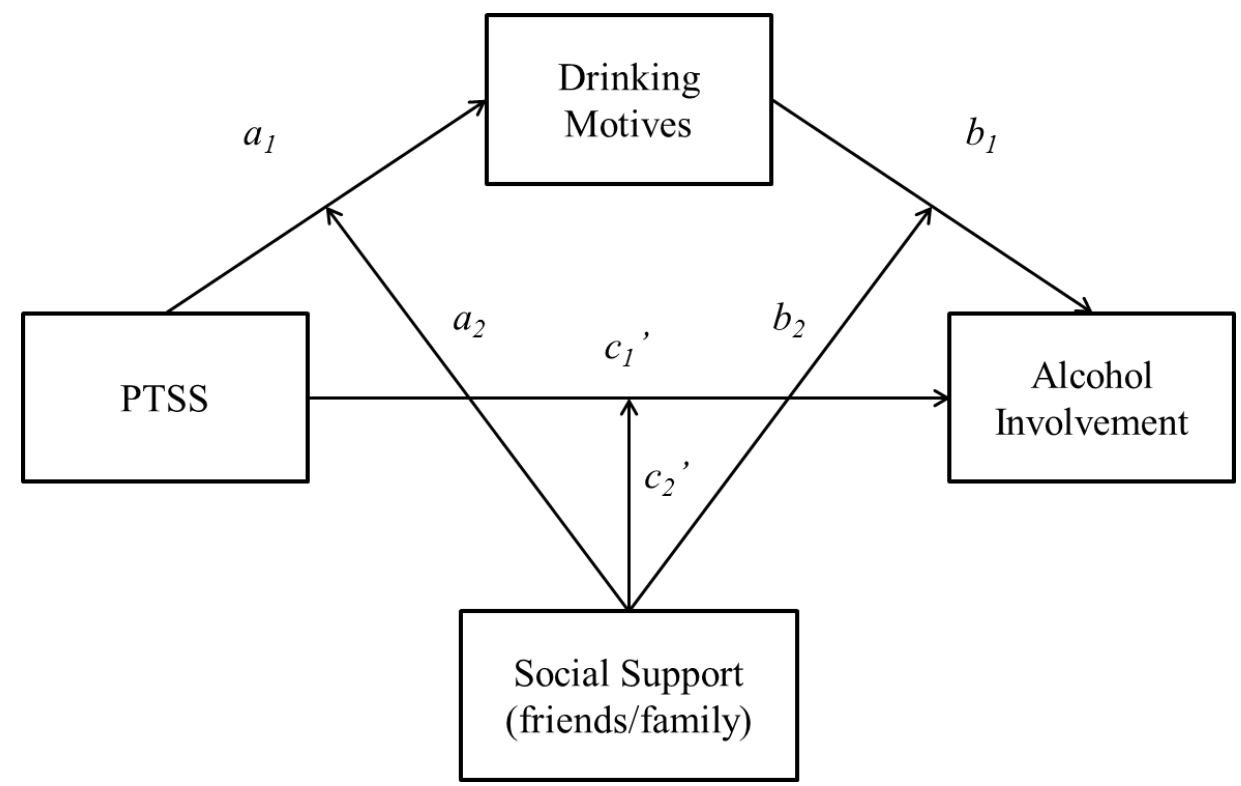

Figure 1. Conceptual model of the conditional indirect effect of PTSD symptoms (PTSS) on alcohol involvement through drinking motives. 


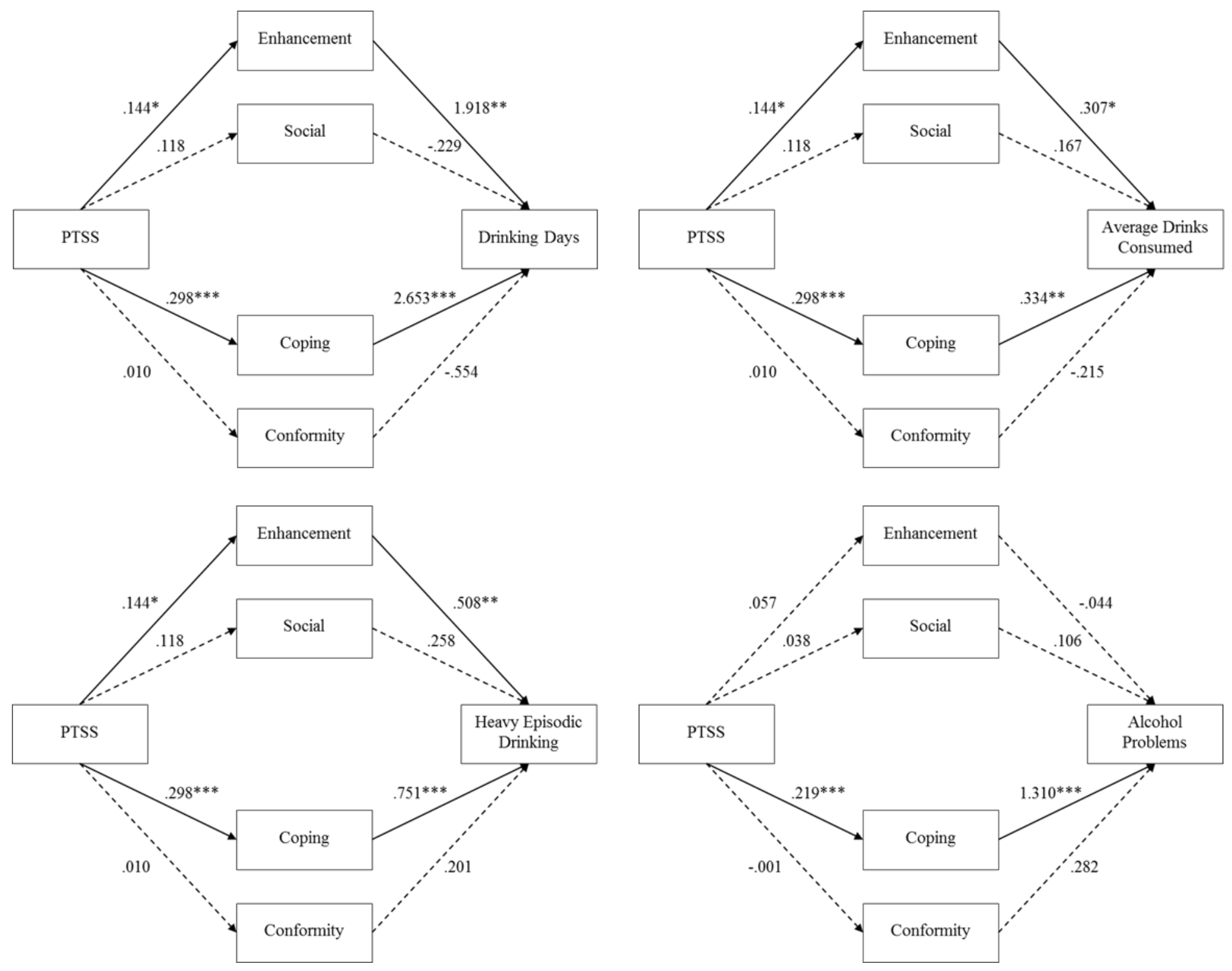

Figure 2. Parallel mediation models of the association between posttraumatic stress symptoms and alcohol involvement 


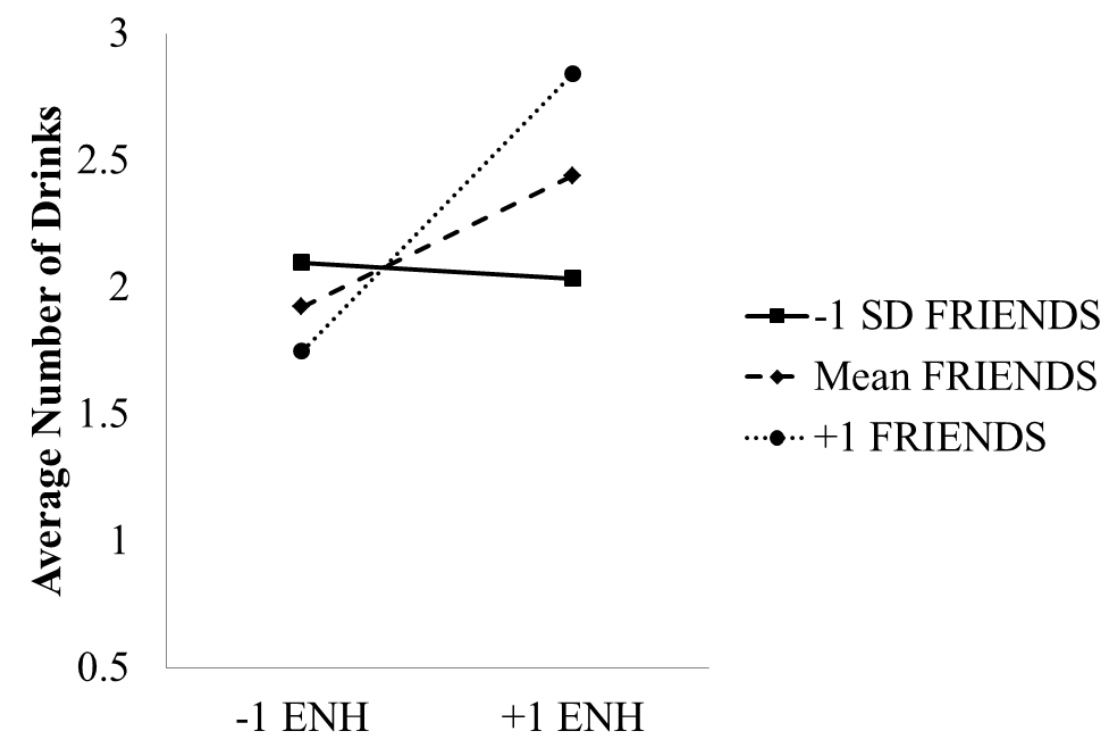

Figure 3. Moderating effect of perceived support from friends (FRIENDS) on the association between enhancement motives $(\mathrm{ENH})$ and average number of drinks consumed. 
Table 1. Descriptive statistics and intercorrelations

\begin{tabular}{|c|c|c|c|c|c|c|c|c|c|c|c|c|c|c|c|}
\hline & $\mathrm{M}$ & SD & Min & Max & 1 & 2 & 3 & 4 & 5 & 6 & 7 & 8 & 9 & 10 & 11 \\
\hline 1. PTSS & 7.66 & 4.09 & 4 & 20 & 1.00 & & & & & & & & & & \\
\hline 2. $\mathrm{ENH}$ & 2.09 & 0.94 & 1 & 5 & $.16^{+}$ & 1.00 & & & & & & & & & \\
\hline 3. SOC & 2.06 & 1.07 & 1 & 5 & $.17^{+}$ & .67 & 1.00 & & & & & & & & \\
\hline 4. DTC & 1.69 & 0.96 & 1 & 5 & $.46^{\ddagger}$ & .52 & .48 & 1.00 & & & & & & & \\
\hline 5. CONF & 1.16 & 0.40 & 1 & 4 & .09 & .34 & .39 & $.26^{\ddagger}$ & 1.00 & & & & & & \\
\hline 6. FRIENDS & 3.48 & 0.81 & 1 & 5 & -.28 & -.04 & -.09 & -.30 & -.06 & 1.00 & & & & & \\
\hline 7. FAMILY & 3.66 & 0.77 & 1 & 5 & -.19 & -.17 & $-.15^{+}$ & $-.31^{\ddagger}$ & -.04 & $.38^{\ddagger}$ & 1.00 & & & & \\
\hline 8. ALCDAYS & 9.82 & 8.70 & 1 & 30 & $.12 *$ & $.31^{\ddagger}$ & .20 & $.33^{\ddagger}$ & .10 & -.04 & -.07 & 1.00 & & & \\
\hline 9. A VEALC & 2.15 & 1.67 & .5 & 10 & $.22+$ & .35 & .32 & .35 & $.10^{*}$ & -.04 & -.07 & $.18^{+}$ & 1.00 & & \\
\hline 10. AUDIT & 5.77 & 4.67 & 1 & 29 & .28 & .49 & $.45^{*}$ & .60 & .20 & $-.13^{\ddagger}$ & $-.15^{t}$ & .49 & $.60^{\ddagger}$ & 1.00 & \\
\hline 11. HED (Y/N) & - & - & - & - & $.21^{+}$ & .42 & .39 & .42 & .19 & $-.13 *$ & $-.10^{*}$ & .34 & $.51^{*}$ & .62 & 1.00 \\
\hline
\end{tabular}

‡ Significant at $p<.01 ; *$ Significant at $p<.05 ;$

PTSS = posttraumatic stres s symptoms $;$ ENH = enhancement motives $;$ SOC = social motives $;$ DTC = coping motives $;$ CONF $=$ conformity motives $;$ FRIENDS

= perceived support from friends; FAMILY = perceived support from family; ALCDAYS = number of drinking days in past month; AVEALC = average

number of drinks consumed per day; AUDIT = total score on 10-item Alcohol Use Disorders Identification Test; HED = heavy epis odic drinking during past 30

days 
Table 2. Unstandardized coefficients for conditional indirect effect of posttraumatic stress symptoms and alcohol involvement through drinking to cope motives

\begin{tabular}{|c|c|c|c|c|c|c|c|c|}
\hline \multirow[b]{2}{*}{ Path/Effect } & \multicolumn{2}{|c|}{ ALCDAYS } & \multicolumn{2}{|c|}{ A VEALC } & \multicolumn{2}{|c|}{ ARP } & \multicolumn{2}{|c|}{ HED } \\
\hline & $B(\mathrm{SE})$ & $95 \% \mathrm{BC} \mathrm{CI}$ & $B(\mathrm{SE})$ & $95 \% \mathrm{BC} \mathrm{CI}$ & $B(\mathrm{SE})$ & $95 \% \mathrm{BC} \mathrm{CI}$ & $B(\mathrm{SE})$ & $95 \% \mathrm{BC} \mathrm{CI}$ \\
\hline $\begin{array}{l}\text { Perceived Support: FRIENDS } \\
a \text { (PTSS-DTC) }\end{array}$ & $0.27(.05)^{\dagger}$ & {$[0.16 ; 0.37]$} & $0.27(.05)^{\dagger}$ & {$[0.16 ; 0.37]$} & $0.19(.05)^{\dagger}$ & {$[0.09 ; 0.28]$} & $0.27(.05)^{\dagger}$ & {$[0.16 ; 0.37]$} \\
\hline$b$ (DTC-alcohol) & $2.85(.62)^{\dagger}$ & {$[1.63 ; 4.07]$} & $0.41(.12)^{\dagger}$ & {$[0.17 ; 0.64]$} & $1.35(.19)^{\dagger}$ & {$[0.99 ; 1.72]$} & $0.83(.21)^{\dagger}$ & {$[0.42 ; 1.24]$} \\
\hline$c^{\prime}$ (PTSS-alcohol) & $0.43(.55)$ & {$[-0.64 ; 1.50]$} & $0.17(.10)$ & {$[-0.04 ; 0.37]$} & $-0.02(.16)$ & {$[-0.32 ; 0.29]$} & $0.05(.16)$ & {$[-0.27 ; 0.37]$} \\
\hline$a b$ for $-1 S D$ FRIENDS & $1.03(.39)$ & {$[0.41 ; 1.90]$} & $0.17(.07)$ & {$[0.07 ; 0.35]$} & $\mathbf{0 . 3 0}(.13)$ & {$[0.11 ; 0.64]$} & $0.27(.12)$ & {$[0.08 ; 0.50]$} \\
\hline$a b$ for mean FRIENDS & $0.76(.27)$ & {$[0.32 ; 1.37]$} & $0.11(.05)$ & {$[0.04 ; 0.22]$} & $0.25(.10)$ & {$[0.09 ; 0.48]$} & $0.22(.09)$ & {$[0.08 ; 0.40]$} \\
\hline$a b$ for $+1 S D$ FRIENDS & $0.52(.32)$ & {$[0.09 ; 1.40]$} & $0.06(.05)$ & {$[-0.02 ; 0.19]$} & $0.18(.13)$ & {$[-0.01 ; 0.52]$} & $0.17(.10)$ & {$[0.04 ; 0.45]$} \\
\hline $\begin{array}{l}\text { Perceived Support: FAMILY } \\
a \text { (PTSS-DTC) }\end{array}$ & $0.28(.05)^{\dagger}$ & {$[0.18 ; 0.39]$} & $0.28(.05)^{\dagger}$ & {$[0.18 ; 0.39]$} & $0.20(.05)^{\dagger}$ & {$[0.10 ; 0.30]$} & $0.28(.05)^{\dagger}$ & {$[0.18 ; 0.39]$} \\
\hline$b$ (DTC-alcohol) & $2.79(.62)^{\dagger}$ & {$[1.56 ; 4.01]$} & $0.46(.12)^{\dagger}$ & {$[0.23 ; 0.69]$} & $1.33(.19)^{\dagger}$ & {$[0.96 ; 1.69]$} & $0.89(.22)^{\dagger}$ & {$[0.46 ; 1.32]$} \\
\hline$c^{\prime}$ (PTSS-alcohol) & $0.24(.55)$ & {$[-0.84 ; 1.31]$} & $0.15(.10)$ & {$[-0.06 ; 0.35]$} & $-0.05(.16)$ & {$[-0.36 ; 0.26]$} & $0.04(.16)$ & {$[-0.28 ; 0.36]$} \\
\hline$a b$ for $-1 S D$ FAMILY & $\mathbf{0 . 7 8}(.33)$ & {$[0.26 ; 1.62]$} & $0.08(.06)$ & {$[-0.00 ; 0.24]$} & $0.22(.12)$ & {$[0.04 ; 0.53]$} & $0.19(.10)$ & {$[0.02 ; 0.42]$} \\
\hline$a b$ for mean FAMILY & $0.78(.28)$ & {$[0.33 ; 1.39]$} & $0.13(.05)$ & {$[0.05 ; 0.25]$} & $0.27(.10)$ & {$[0.12 ; 0.50]$} & $0.25(.10)$ & {$[0.09 ; 0.47]$} \\
\hline$a b$ for $+1 S D$ FAMILY & $0.79(.41)$ & {$[0.18 ; 1.84]$} & $0.18(.08)$ & {$[0.05 ; 0.37]$} & $0.31(.13)$ & {$[0.12 ; 0.67]$} & $0.31(.15)$ & {$[0.09 ; 0.68]$} \\
\hline
\end{tabular}

${ }^{\dagger}$ coefficients significant at $p<.001 ;{ }^{\dagger}$ coefficients significant at $p<.01 ; *$ coefficients significant at $p<.05$

indirect effects in bold are statistically significant; PTSS = Posttraumatic Stress Symptoms; DTC = drinking to cope motives;

FRIENDS = perceived support from friends; FAMILY = perceived support from family; ALCDAYS = number of drinking days in past month;

AVEALC = average number of drinks consumed per day; ARP = score for alcohol-related problems using adapted, 7-item Alcohol Use Dis orders Identification

Test; HED = heavy epis odic drinking within the past 30 days 
Table 3. Unstandardized coefficients for conditional indirect effect of posttraumatic stress symptoms and alcohol involvement through enhancement drinking motives

\begin{tabular}{|c|c|c|c|c|c|c|c|c|}
\hline \multirow[b]{2}{*}{ Path/Effect } & \multicolumn{2}{|c|}{ ALCDAYS } & \multicolumn{2}{|c|}{ AVEALC } & \multicolumn{2}{|c|}{ ARP } & \multicolumn{2}{|c|}{ HED } \\
\hline & $B(\mathrm{SE})$ & $95 \% \mathrm{BC} \mathrm{CI}$ & $B(\mathrm{SE})$ & $95 \% \mathrm{BC} \mathrm{CI}$ & $B(\mathrm{SE})$ & $95 \% \mathrm{BC} \mathrm{CI}$ & $B(\mathrm{SE})$ & $95 \% \mathrm{BC} \mathrm{CI}$ \\
\hline $\begin{array}{l}\text { Perceived Support: FRIENDS } \\
a \text { (PTSS-ENH) }\end{array}$ & $0.13(.06)^{*}$ & {$[0.01 ; 0.25]$} & $0.13(.06)^{*}$ & {$[0.01 ; 0.25]$} & $0.05(.06)$ & {$[-0.06 ; 0.15]$} & $0.13(.06)^{*}$ & {$[0.01 ; 0.25]$} \\
\hline$b$ (ENH-alcohol) & $2.00(.63)^{\ddagger}$ & {$[0.76 ; 3.24]$} & $0.28(.12)^{*}$ & {$[0.04 ; 0.51]$} & $0.01(.19)$ & {$[-0.36 ; 0.37]$} & $0.51(.18)$ & {$[0.15 ; 0.87]$} \\
\hline$c^{\prime}$ (PTSS-alcohol) & $0.43(.55)$ & {$[-0.64 ; 1.50)$} & $0.17(.10)$ & {$[-0.04 ; 0.37]$} & $-0.02(.16)$ & {$[-0.32 ; 0.29]$} & $0.05(.16)$ & {$[-0.27 ; 0.37]$} \\
\hline$a b$ for $-1 S D$ FRIENDS & $0.24(.22)$ & {$[-0.08 ; 0.79]$} & $-0.01(.04)$ & {$[-0.11 ; 0.06]$} & $-0.00(.05)$ & {$[-0.13 ; 0.09]$} & $0.04(.07)$ & {$[-0.10 ; 0.18)$} \\
\hline$a b$ for mean FRIENDS & $0.26(.15)$ & {$[0.04 ; 0.64]$} & $0.04(.02)$ & {$[0.00 ; 0.10]$} & $0.00(.02)$ & {$[-0.03 ; 0.04]$} & $0.07(.05)$ & {$[0.00 ; 0.18]$} \\
\hline$a b$ for $+1 S D$ FRIENDS & $0.18(.23)$ & {$[-0.20 ; 0.75]$} & $0.04(.05)$ & {$[-0.03 ; 0.16]$} & $-0.00(.02)$ & {$[-0.05 ; 0.04]$} & $0.05(.07)$ & {$[-0.06 ; 0.25]$} \\
\hline $\begin{array}{l}\text { Perceived Support: FAMILY } \\
a \text { (PTSS-ENH) }\end{array}$ & $0.14(.06)^{*}$ & {$[0.02 ; 0.26]$} & $0.14(.06)^{*}$ & {$[0.02 ; 0.26]$} & $0.05(.06)$ & {$[-0.06 ; 0.16]$} & $0.14(.06)^{*}$ & {$[0.02 ; 0.26]$} \\
\hline$b(\mathrm{ENH}-\mathrm{alcohol})$ & $1.86(.64)^{\ddagger}$ & {$[0.61 ; 3.12]$} & $0.34(.12)$ & {$[0.10 ; 0.57]$} & $0.00(.19)$ & {$[-0.37 ; 0.37]$} & $0.56(.19) \ddagger$ & {$[0.19 ; 0.92]$} \\
\hline$c^{\prime}$ (PTSS-alcohol) & $0.24(.55)$ & {$[-0.84 ; 1.31]$} & $0.15(.10)$ & {$[-0.06 ; 0.35]$} & $-0.05(.16)$ & {$[-0.36 ; 0.26]$} & $0.04(.16)$ & {$[-0.28 ; 0.36]$} \\
\hline$a b$ for $-1 S D$ FAMILY & $0.33(.25)$ & {$[0.00 ; 1.01]$} & $0.04(.04)$ & {$[-0.03 ; 0.16]$} & $0.02(.05)$ & {$[-0.05 ; 0.19]$} & $0.09(.09)$ & {$[-0.02 ; 0.27]$} \\
\hline$a b$ for mean FAMILY & $0.26(.15)$ & {$[0.04 ; 0.64]$} & $0.05(.03)$ & {$[0.01 ; 0.11]$} & $0.00(.02)$ & {$[-0.04 ; 0.04]$} & $0.08(.05)$ & {$[0.01 ; 0.19]$} \\
\hline$a b$ for $+1 S D$ FAMILY & $0.20(.18)$ & {$[-0.02 ; 0.74]$} & $0.05(.04)$ & {$[-0.00 ; 0.15]$} & $-0.00(.02)$ & {$[-0.09 ; 0.02]$} & $0.07(.06)$ & {$[-0.01 ; 0.26]$} \\
\hline
\end{tabular}

${ }_{\dagger}$ coefficients significant at $p<.001 ; \ddagger$ coefficients significant at $p<.01 ; *$ coefficients significant at $p<.05 ;$

indirect effects in bold are statistically significant; PTSS = Posttraumatic Stress Symptoms; ENH = enhancement drinking motives;

FRIENDS = perceived support from friends; FAMILY = perceived support from family; ALCDAYS = number of drinking days in past month;

AVEALC = average number of drinks consumed per day; ARP = score for alcohol-related problems using adapted, 7-item Alcohol Use Dis orders Identification

Test; HED = heavy episodic drinking within the past 30 days 